\title{
ALERT SYSTEM IN THE CASE OF EXCESS WITHDRAWAL OR RISE UP OF GROUNDWATER IN THE SENSITIVE AREAS: THE INSTALLATION OF THE ALICE SYSTEM IN THE VINEYARD OF EL HUAICO, PEDERNAL, ARGENTINA
}

\author{
Z. BOUKALOVÁ ${ }^{1} \&$ Z. KŘIVÁNEK ${ }^{2}$ \\ ${ }^{1}$ VODNÍ ZDROJE, a.s.; Czech Republic. \\ ${ }^{2}$ České Centrum pro Vědu a Společnost; Czech Republic.
}

\begin{abstract}
The paper deals with a description of the technical components of the system ALICE and their practical application under the project of the EUREKA programme: "ALert system In Case of Excess Withdrawal or Rise up of Groundwater in the Sensitive Areas". This project is running from March 2014 to December 2016 under the coordination of the company VODNÍ ZDROJE, a.s. from the Czech Republic. Its partners are the Czech Centre for Science and Society, ATOS Spain and BOSC from Lithuania.

The project deals with developing a new generation warning and monitoring system based on the implementation of interoperable interfaces that will enable early spotting of extreme drops or rises in groundwater levels in areas that are directly dependent on their stability.

The ALICE system is tested in 2016 on the pilot plant, situated in the vineyards (San Juan province, Pedernal, Argentina) and main aim of this testing is to collect enough data for the evaluation of the in situ irrigation system.

The main focus of this paper is a description of the process of the pilot plant installation at the site in Valle Pedernal and the technical as well as economic components of the system.

Keywords: alert system, Argentina, groundwater, sensors, water management, sustainable irrigation, wine farms.
\end{abstract}

\section{INTRODUCTION - ALICE PROJECT}

The project ALICE ("ALert system In Case of Excess withdrawal or rise up of groundwater in the sensitive areas") deals with developing a new generation warning and monitoring system based on the implementation of interoperable interfaces that will enable early spotting of extreme drops or rises of groundwater levels in areas that are directly dependent on their stability.

The testing of the ALICE system is conducted at the vineyard of El Huaico in Valle Pedernal, province of San Juan, Argentina, where the own WSN (Wireless Sensor Network) system has been designed.

What makes this site interesting is the use of groundwater for irrigation and as well the uneven vine growth, which is affecting the wine quality and productivity.

\section{THE SITE OF EL HUAICO, PEDERNAL}

The farm of El Huaico covers an area of approx. 354 ha (of which 80 ha are currently productive vineyards where the Malbec variety has been grown since 2008) in the southern part of the Pedernal valley. 


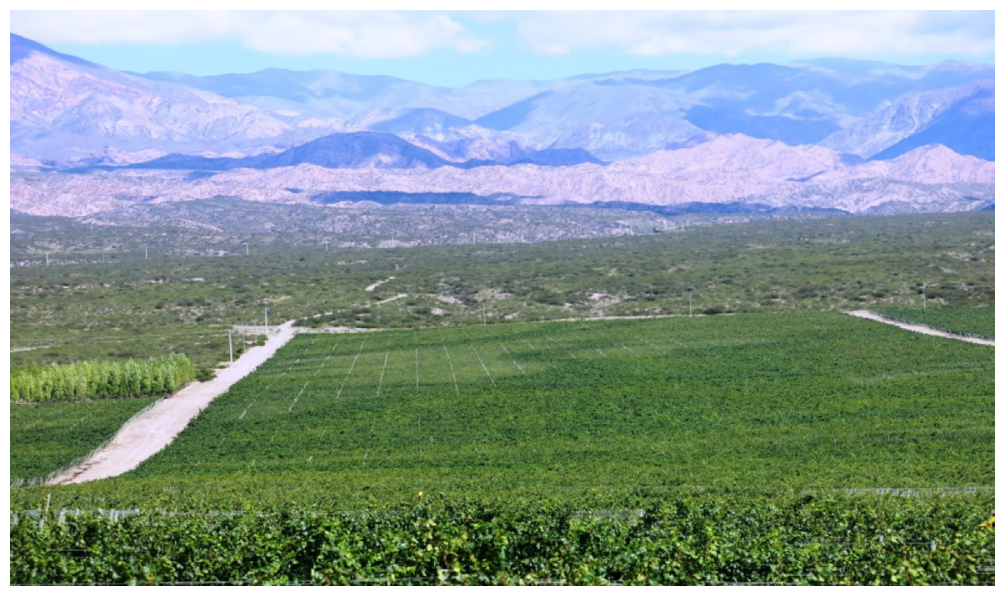

Figure 1: Vineyard El Huaico, Pedernal, San Juan, Argentina. (on the picture could be seen that some plants are being considerably lower and are creating little islands in the middle of more vigorous vines)

In the pilot area, soils are alluvial, made of gravel of varying granulometry combined with sands, silts and clays. The proportions of the materials vary depending on the place. The soils have different physical properties as well as different water retention capacity and generally, the soils are poor showing low content of organic matter. As for the climatic conditions in the area, the highest average temperatures range between $28^{\circ}$ and $24^{\circ} \mathrm{C}$ in the period of grape ripening from January to April, while the lowest average temperatures range between $10^{\circ}$ and $4^{\circ} \mathrm{C}$. The average annual precipitation - despite being higher than in the other valleys within the province - is low, reaching only a little more than $150 \mathrm{~mm}$. In the area of interest, water for irrigation is extracted exclusively from groundwater sources by means of wells (1).

The pilot installation of the ALICE system technical equipment in the vineyard of El Huaico (see Fig. 1) was carried out in two stages (Stage I: September 2015, Stage II: January/February 2016) and followed the hydrogeological and pedological surveys of the site in March 2015. In the year 2015, the chemical content and potential pollution of the soils were monitored as well, to evaluate if the vineyard intensive irrigation could influence the groundwater quality in the pilot area and if the soil (due to natural conditions or overfertilization) is a potential source of pollution (for example nitrate leaching to the groundwater) in the valley. However, the contamination was not determined and from the results is clear as well, that the quality of soils is not influencing groundwater quality in the area.

\section{RESULTS OF THE SURVEY ON THE VINEYARD - UNEVEN PLANTS GROWTH}

During the reconnaissance survey in March 2015, it had been determined that in some parts of the vineyard the vine did not reach the required height, the plants being considerably lower and creating little islands in the middle of more vigorous vines. In other parts of the vineyard, in turn, there are overgrown plants which seem to be very good quality and resilient but do not bear grapes. Both of these extreme situations concerning good vine growth at the site are considered serious, even critical, by the vineyard management. Therefore, it is 

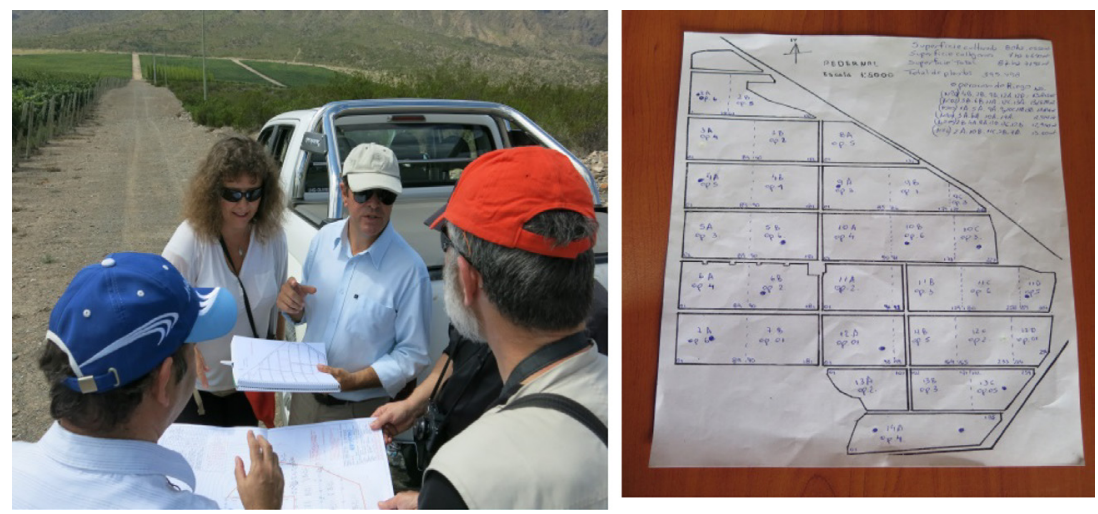

Figure 2: The vineyard divided into segments.

Table 1: Use of the colours - legend.

\begin{tabular}{|c|c|c|}
\hline Colour & Meaning & Plant growth \\
\hline Red & Failure, with letters from $A=1$ to $G=7$ & Stunts \\
\hline White & Shoots reaching the first fixed wire (single) & $\begin{array}{l}\text { Extremely } \\
\text { small }\end{array}$ \\
\hline Yellow & Shoots between the first fixed wire and the couple of fixed wires & Small \\
\hline Bright green & Shoots between the couple of fixed wires and the top wire (last) & Medium \\
\hline Dark green & Shoots at approx. $40 \mathrm{~cm}$ above the top wire (last) & Optimum \\
\hline Black & Shoots with excessive growth & $\begin{array}{l}\text { Excessive } \\
\text { vigour }\end{array}$ \\
\hline
\end{tabular}

necessary to eliminate such differences in vine growth by a change in management methods in the future.

The most likely cause of the uneven vine growth in the Pedernal valley was found to be the spatially uneven water distribution (2), which is likely to be caused by hydrogeological conditions of the zone as well as the distribution of preferential pathways of ground and subsurface water. The excessive growth of some other plants can be accounted for by an oversupply of nutrients as well as other factors.

Based on this assumption, problematic areas of the site were identified. The vineyard was divided into various sections to be monitored individually (see Fig. 2).

In these sections of the pilot vineyard El Huaico, the growth of individual plants was monitored in 2014-2015 and 6 "growth categories" were recognised. For each category, the different colour was chosen, for the vineyard visualisation (see Table 1 - for marking the vine plants growth, following colours have been used).

In Fig. 3, section 4A is chosen as an example to display the use of colours which, are described in Table 1. 

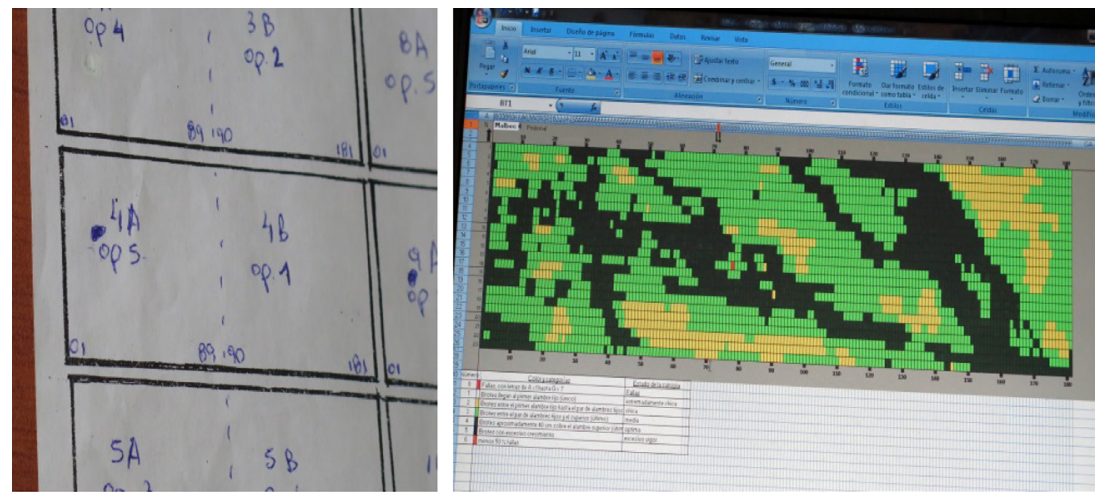

Figure 3: The segment 4A.

To determine the development in time of individual vineyard sections and their parts that show similar characteristics, sensors for determining soil moisture, soil temperature and electrical conductivity at a given place have been used.

\section{RESULTS OF THE SURVEY ON THE VINEYARD - CONTAMINATION}

To predict the potential groundwater pollution in the area, we monitored the soil quality. The analysis of soil samples focused on its composition (for the general soil property definition), further on the analysis of nitrates and heavy metals content in the soil. The nitrates are varying in the pilot area, and for the detail location of the potential nitrate pollution sources, it must be considered the mapping in more detailed sampling steps. Regarding the heavy metals concentrations, the contents of arsenic, total chromium, cadmium, cobalt, copper, nickel, lead, mercury, vanadium, and zinc in the soil were determined.

The comparison of the results concerning heavy metal contents in soil samples with the limits of the Methodological Instructions of the Ministry of the Environment of the Czech Republic clearly shows that all heavy metals are well below the threshold values with the exception of arsenic. The arsenic content in soils at the site is approximately two orders of magnitude higher than the recommended threshold value. This increased occurrence, which is probably of natural origin, has no impact on vine growth, as the contents are about the same in places of regular vine growth and in those displaying reduced growth, and probably is not influencing the groundwater quality in the Pedernal Valley. However, it is advisable to determine the content of arsenic in water, and as well in a soil leachate at the site regularly, to assess the possible impact on the health of the residents. Nevertheless, we can rule out the effect of arsenic on vine growth.

The samples of soil are marked A, B,.., H and were taken from 3 places where noticeable differences in vine growth had been observed, from the three different depths $(20 \mathrm{~cm} / 60 \mathrm{~cm}$ $/ 110 \mathrm{~cm}$ bellow the terrain).

\section{ALICE SYSTEM IN SITU IMPLEMENTATION}

On the vineyard of El Huaico, sensors were placed into the probes, at the depths of $40 \mathrm{~cm}$, $65 \mathrm{~cm}$, and $110 \mathrm{~cm}$ respectively depending on soil texture and the sizes of the plants' root systems. Subsequently, the sensors were connected to nodes (each node can be connected up to 4 different sensors) - see Fig. 4. As for the sensors themselves, the network is open, 
Table 2: Evaluation of heavy metal contents in soil. Unit: $\mathrm{mg} / \mathrm{kg}$ of dry matter.

\begin{tabular}{lrrrrrrrrr}
\hline \multicolumn{1}{c}{ metal } & $\mathrm{A}$ & $\mathrm{B}$ & $\mathrm{C}$ & $\mathrm{D}$ & $\mathrm{E}$ & $\mathrm{F}$ & $\mathrm{G}$ & $\mathrm{H}$ & Limits \\
\hline arsenic & 23.2 & 23.8 & 23.1 & 23.8 & 18 & 21.8 & 24.8 & 10.1 & 0.61 \\
chromium & 38.2 & 30.7 & 38.7 & 30.2 & 27.9 & 31.4 & 31.1 & 27.5 & - \\
cadmium & 0.5 & 0.5 & 0.5 & 0.5 & 0.5 & 0.5 & 0.5 & 0.5 & 70 \\
cobalt & 10.5 & 90.5 & 9.74 & 7.28 & 6.59 & 5.09 & 3.09 & 3.64 & 23 \\
copper & 22.3 & 22.3 & 25.8 & 23.9 & 31.3 & 24.1 & 23.5 & 28.7 & 3,100 \\
nickel & 16.5 & 16.7 & 25.2 & 22 & 22.6 & 21.9 & 23.5 & 21.5 & 1,500 \\
lead & 10 & 8.95 & 20 & 12.9 & 10.1 & 11.2 & 10.1 & 10.7 & 400 \\
mercury & 0.41 & 0.19 & 0.06 & 0.04 & 0.04 & 0.02 & 0.02 & 0.02 & 10 \\
vanadium & 75.7 & 65 & 81.1 & 78.8 & 72.5 & 69 & 78.5 & 87.5 & 390 \\
zinc & 64.1 & 67.8 & 74.4 & 70.8 & 70.7 & 77.7 & 68.5 & 74 & 23,000 \\
\hline
\end{tabular}
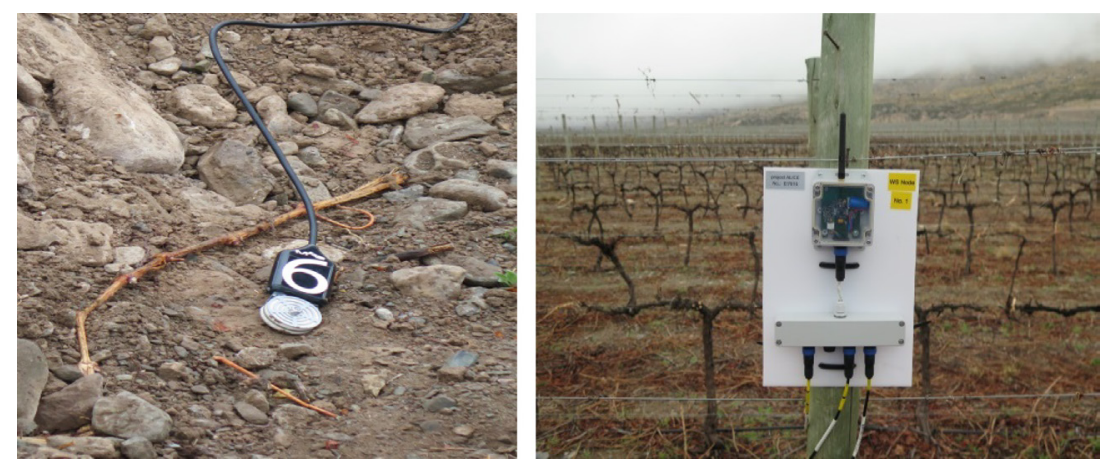

Figure 4: The sensor and the nod in the field.

making it possible to use sensors from various manufacturers on the condition that they comply with the communication standard SDI 12.

The WSN (Wireless Sensor Network) system - see Fig. 5 - has been designed considering the fact that the vineyard of El Huaico pilot at Pedernal is not a large site (and the distances between nodes are expected to be hundreds of metres at most). As for data flow, the network is designed in such a way that the network nodes transmit the identification of each particular sensor + the value of the measured electric quantity, while the Network Coordinator Node interprets the measured electric quantities as a specific phenomenon and its value (with due calibration) and sends them to the data server.

In the vineyard of El Huaico, the optimal net of sensors was designed, based on the hydrogeological and pedological survey of the area, as well experiences of the vineyard manager (Table2: suggested optimal distribution of sensors in the vineyard of El Huaico). 


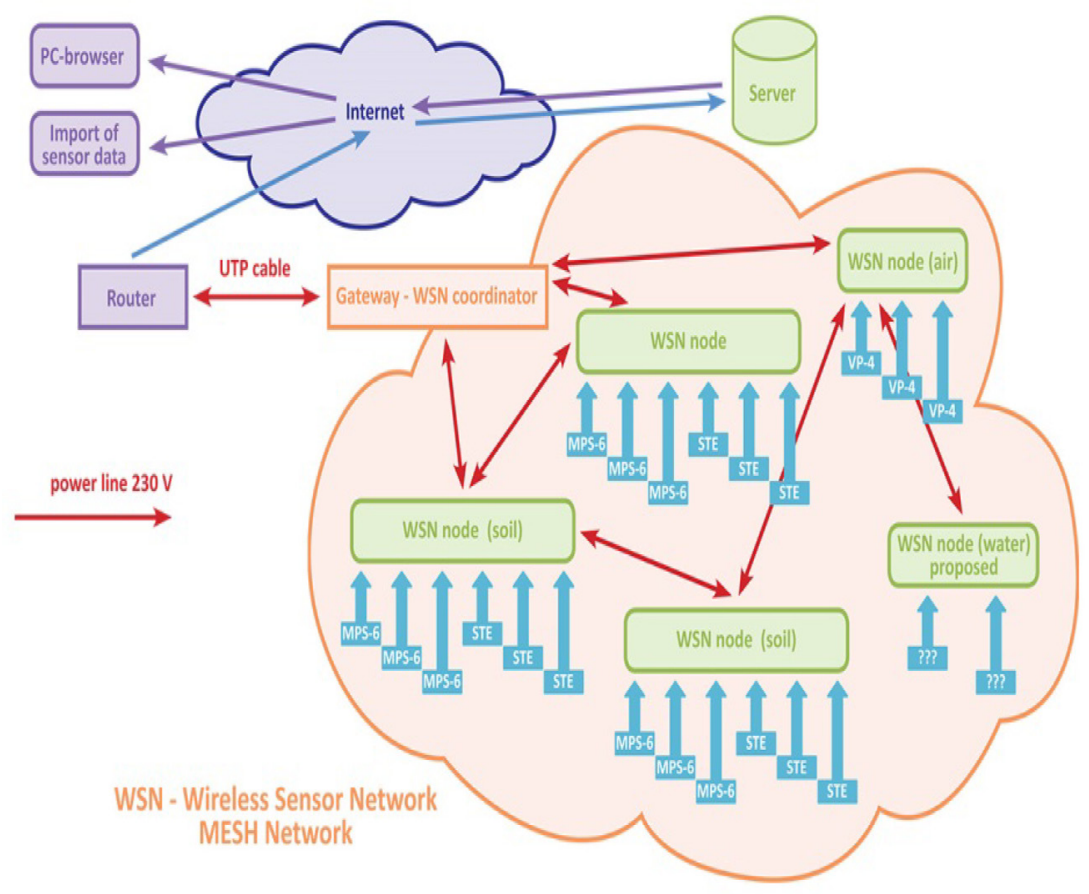

Figure 5: The WSN Network.

The ALICE system is an end user support system (DSS) for collecting data to enhance decision-making. Generally the ALICE system consists of the following technological units: the sensor network itself placed in the vineyard (WSN), data transmission system, data storage system, and system for visualising the measured data.

\section{THE ALICE SYSTEM PILOT PLANT}

On the ALICE pilot plant, installed in situ at the vineyard in October 2015, the functionality of data collection and transmission for further visualisation are being tested in 2016.

The valley of Pedernal is indeed an extreme site to test the ALICE system. As the pilot area is not covered by a mobile signal that could be used for transmitting the monitoring data to a central server, it was necessary to establish a satellite Internet connection on the site. Data are collected several times a day, the frequency depending on the customer's requirements. As the data collection does not require high data transmission capacity, the cheapest satellite Internet connection transmitting up to several tens of KB per day is sufficient for Pedernal.

\section{ECONOMIC COMPONENTS OF THE ALICE SYSTEM}

As a result of the cooperation with potential end users of the ALICE system in the province of San Juan (and possibly Mendoza), the economic components of the ALICE system have been determined (further marked as blocks A, B, C, and D) for the general future ALICE system implementation. However, they do not have to be fully used at each site. Everything depends on the readiness of the vineyard and the customer's requirements: 
Table 3: Suggested distribution of the nodes in the vineyard.

\begin{tabular}{llllll}
\hline Node & $\begin{array}{c}\text { What will be } \\
\text { monitored }\end{array}$ & Block & Row & Gap & Comments \\
\hline 1 & Soil, Air & 2 & 15 & 14 & \\
2 & Soil & 4 & 34 & 9 & Installed in October 2015 for pilot testing \\
3 & Soil, Air & 5 & 130 & 12 & Installed in October 2015 for pilot testing \\
4 & Soil & 6 & 110 & 12 & \\
5 & Soil & 7 & 50 & 11 & \\
6 & Soil & 9 & 25 & 12 & Installed in October 2015 for pilot testing \\
7 & Soil & 10 & 107 & 14 & \\
8 & Soil & 10 & 211 & 10 & \\
9 & Soil, Air & 11 & 260 & 14 & \\
10 & Soil & 12 & 79 & 16 & \\
11 & Soil & 13 & 222 & 9 & \\
12 & Soil, Air & 14 & 147 & 11 & \\
13 & Soil & 14 & 45 & 10 & \\
14 & Well & 3 & & &
\end{tabular}

Block A (know-how / the cost of the system): Assessment of pilot sites, revaluation of hydrogeological and hydrological conditions, evaluation of satellite images, definition of the required data and their integration into the system. Determination of areas suitable for the placement of measurement points, and a model of the site, if needed. Output: design for the placement of sensor nodes and sensor types at the site - optimum solution (design for the sensor distribution so as to obtain maximum useful information for the lowest price possible). The optimisation criterion is the price/acquired information ratio.

Block B (know-how / cost of the system): wireless sensor network system, wireless system for data transmission, transmission to a server, data storage and a client application for looking through the data including simple analysis at non-professional level (e.g. summaries of the measured data based on input criteria), the recommendation for a sensor type and manufacturer based on the user's requirements. Purchase of nodes, sensors, equipment, etc. Output: delivery of an optimum operating wireless network. Data transfer to a server and their visualisation.

Block C (service): operation and maintenance of point B (the wireless network itself). 
Block D (superstructure): other related analyses of data and situations according to the customer's requirements (e.g. amount of water utilizable for irrigation at a given moment and related end-user applications, etc.).

The business model concerning blocks A, B, C, and D will be defined on the basis of the results of the ALICE project survey during the year 2016, and the commercial price of each economic component (block) will be discussed at a workshop of the international project team in San Juan at the beginning of November 2016.

\section{CONCLUSIONS}

The ALICE project is expected to define a user-friendly and cost-effective, innovative interoperable system based on a combination of sensors and a WSN - its advantage being its easy integration into the control and monitoring systems in using data collecting and processing.

Generally, the ALICE system is developed for geographical areas where the stability of groundwater levels is a vital precondition for their agricultural use and for settings where groundwater level can be controlled. The challenge for sustainable wine crop production is to achieve optimised yield (in quantity and quality) and farm income with a minimum of inputs (nutrients, water, but also energy, pesticides, herbicides, money), while preserving the environment.

Resulting from the pilot implementation of the ALICE system in Valle Pedernal, a number of discussions are going on with potential end users of the system. The end users' attitude clearly shows a marked interest in the implementation of the ALICE system at selected vineyards in the San Juan province, and possibly Mendoza as well. Potential new customers have been addressed and encouraged to take active part in the ongoing definition of the transfer conditions and, if possible, also in monitoring of the ALICE pilot plant in the Pedernal vineyard on the so-called open days that will be organised in November 2016 in San Juan, and further in the definition of a commercial application of ALICE suitable both for vineyards and other irrigated agricultural areas. We expect that the ALICE system will be on the open market from January 2017.

\section{ACKNOWLEDGEMENTS}

This paper was developed thanks to the E!7616 EUREKA project ALICE, co-financed by the Ministry of Education, Young and Sports, Czech Republic (50\%) and organizations VODNÍ ZDROJE a.s. and České Centrum pro Vědu a Společnost (50\%).

\section{REFERENCES}

[1] Dolling, O., Proyecto CICITCA (21/1939): Impacto del reuso del aqua en el proceso de deserification en San Juan y su relacion con la variabilidad climatica. Informe Academico Final (2011 - 2013). Universidad Nacional de San Juan, Marzo 2014.

[2] Boukalová, Z. \& Křivánek, Z., Alice- an effective tool of groundwater-level regulation for large vine growing areas. River Basin Management VIII, A Coruña, Spain. Print ISBN: 978-1-84564-962-3; eISBN: 978-1-84564-963-0. 